\title{
Popularity, likeability, and risk-taking in middle adolescence
}

\author{
Stephanie Hawke*, Elizabeth Rieger \\ Research School of Psychology, The Australian National University, Canberra, Australia; \\ *Corresponding Author: Stephanie.Hawke@anu.edu.au
}

Received 17 March 2013; revised 18 April 2013; accepted 1 May 2013

Copyright (c) 2013 Stephanie Hawke, Elizabeth Rieger. This is an open access article distributed under the Creative Commons Attribution License, which permits unrestricted use, distribution, and reproduction in any medium, provided the original work is properly cited.

\begin{abstract}
This study investigated the roles of adolescent popularity and likeability in eight domains of risk-taking in Australian grade 9 students (53\% girls). The eight domains included previously examined areas of aggressive behaviours, alcohol use, and sexual intercourse, and areas where there is scarce information, including antisocial activities, unprotected intercourse, body imagerelated risk-taking, unsafe road practices, and stranger-related risk-taking. The results indicated a clear association between popularity and higher risk-taking in five of the eight domains. This is contrasted with likeability, which was not directly related to risk-taking aside from one two-way interaction with gender for sexual intercourse. The findings demonstrate the importance of including a broader range of risk-taking activities when considering popularity, particularly stranger-related risk-taking.
\end{abstract}

Keywords: Adolescence; Popularity; Peer Status; Risk-Taking

\section{INTRODUCTION}

Throughout adolescence, peers become highly influential in forming attitudes and behaviours regarding numerous domains, including risk-taking, which peaks during adolescence [1]. Friends are powerful influences of adolescents' decisions to participate in risk-taking activities, including shoplifting, petty theft, and vandalism [2]. However, adolescent friendships are not the only source of information regarding normative risk-taking practices, as some adolescents are afforded greater status and influence. Two types of status are popularity and likeability, which have some overlapping characteristics, in- cluding prosocial behaviours such as being kind [3,4]. Moreover, some adolescents are described by their peers as being both popular and liked by their year group [5,6], however, there are many differences in the characteristics and behaviours associated with these two types of status.

Despite the literal meaning of the word "popular", research has indicated that adolescents' conceptualisations of this word differ from adults' in that they describe peers who have high social status, power, and influence, rather than to describe peers who are necessarily liked by the year group [4,7]. The profiles of these powerful adolescents are mixed: while some popular students are described as being nice and friendly, many are disliked [8] because they engage in both physical $[6,9]$ and relational aggression [9-11], such as spreading rumours. This form of high social status is contrasted with likeability or social acceptance [12], which refers to adolescents who are also afforded status but they display prosocial characteristics in the absence of bullying and other forms of aggression [4].

Although popular and well-liked adolescents are described as being influential, popularity has been more strongly associated with power and influence [13]. Furthermore, ways in which popular and liked adolescents achieve social status may differ given their associated characteristics and behaviours, although both popular and liked adolescents achieve social status through sporting prowess and physical attractiveness $[5,6]$. Some behaviours appear to be specific to popularity, which is associated with high social visibility [8], part of which may be due to membership of "leading crowds" [14] which set trends and standards by the attitudes and behaviours they display. Social visibility is also achieved through participation in risk-taking behaviours, which are more strongly correlated with popularity than likeability [15].

Researchers have considered the roles of popularity and likeability in risk-taking activities, most commonly 
related to aggressive behaviours $[9,16]$. Popularity is often linked with physical and relational aggression in both boys and girls $[9,11,16]$, whereas likeability is not generally associated with aggression.

The connection between popularity and aggression is complex, as aggression is associated with both popularity and unpopularity [16]. It has been argued that popular adolescents engage in bullying behaviours to intimidate peers and to maintain status [10], and exclude those who in some way pose a threat to their power [17].

Aside from aggressive behaviours, knowledge regarding other antisocial activities is limited. One exception is a study which found that popular males and females engaged in minor delinquent acts, such as stealing items worth less than $\$ 5$, with no significant gender differences [18]. Yet, in general, associations between popularity and shoplifting, vandalism, and breaking school rules remain to be investigated, despite researchers suggesting that it would be beneficial to explore these behaviours in early adolescence rather than substance use and sexual activeties, due to the low prevalence of these latter forms of risk-taking during this period [15].

The roles of popularity and likeability have been investigated in the domain of substance use; most commonly alcohol and cigarette use. One study of grade 7 students found that those who regularly used alcohol and cigarettes were described as being more popular, but not more liked, than non-users at the beginning of the school year, but by the end of the school year there were no differences in popularity or likeability between these two groups [19]. A possible interpretation of this finding is that particular risk-taking activities by popular adolescents determines these behaviours to be "cool", therefore others may be inclined to copy these activities to increase their own status. However, as more students engage in these activities, they are no longer seen as specific to the popular group and the associations between these behaviours and popularity weakens. Another study found that smoking cigarettes in grade 10 was predictive of increases in popularity in grade 12 for boys only, and that grade 10 popularity predicted increased alcohol use in grade 12 for both boys and girls, providing partial support for the bidirectional association between these forms of risktaking and popularity [15].

Investigations considering popularity and other substances, such as marijuana and cocaine, are less common. One exception is a study that found that marijuana use was predicted by high popularity and low grade point average, whereas cocaine use was predicted by low popularity and low grade point average [20]. This suggests that some substance use (alcohol, cigarettes, and marijuana) is considered to be normative and socially accepted [15], whereas other drugs are perceived to be more dangerous and perhaps less "cool". Although there have been increases in ecstasy use among adolescents in recent years [21], associations between popularity and ecstasy use are currently unknown.

Peer status and participation in sexual activities has also been explored, with adolescents engaging in oral sex and sexual intercourse rated as more popular, but not more liked, than those not participating in these activities [22]. Longitudinal investigations have also found that popularity but not likeability in grade 10 predicted higher engagement in sexual intercourse by the end of grade 12 [15]. In terms of peer status and other sexual risk-taking activities such as unprotected intercourse and numbers of sexual partners, one study found that there were no associations between popularity or likeability with more sexual intercourse partners, and that oral sex with multiple partners was linked with lower popularity [22]. This again suggests that some forms of sexual risk-taking are perceived positively, whereas others are not. Although it is currently unknown whether unprotected sexual activeties are associated with peer status, many adolescents engage in unsafe sexual practices, and almost $25 \%$ of sexually active American adolescents reported that their most recent sexual experience coincided with alcohol or drug use [23]. Therefore, it is important to understand potential predictors (such as popularity) of these widespread behaviours.

Another important domain of risk-taking involves eating and weight-related behaviours, with a scarcity of information about these behaviours and peer status despite an abundance of literature surrounding adolescence, body image, and eating behaviours. However, one study investigated popularity along with discrepancies between perceived actual body size and ideal body size in grade 11 and 12 students [24]. This study found that higher popularity was significantly associated with self-reported muscular body shapes for boys, and that lower popularity was associated with self-reported larger body shapes for girls [24]. As both popularity and likeability have been associated with physical attractiveness [5], adolescents who are highly popular or liked may perceive a disproportionate pressure to fit societal norms regarding body shape and size given the attention they receive from others.

Another understudied association between popularity and risk-taking includes road safety, which is somewhat surprising given that having access to a car was noted over 50 years ago [14] as being a strong element of popularity, especially for boys. Understanding this association is vital as young drivers are overrepresented in motor vehicle accident statistics, with over one quarter of all drivers killed or seriously injured each year in Australia aged between 17 and 25 years [25]. Furthermore, the presence of "risky" passengers (i.e., those who scored high on risk-taking activities such as exceeding speed limits) increased the rate of crashes and near-crashes 
among adolescent drivers [26].

As Australian adolescents cannot obtain a motor vehicle learner permit until 16, younger adolescents may participate in other unsafe road safety practices prior to obtaining their license. For example, riding a bicycle without a helmet is a common dangerous activity, with $87.5 \%$ of adolescent bicycle users indicating that they never or rarely wear a bicycle helmet [21]. Furthermore, wearing a safety belt while traveling in a motor vehicle doubles the chances of surviving a serious accident, yet almost one third of people killed in car accidents each year were not wearing safety belts at the time of the crash [25]. Understanding these adolescents' characteristics could help to reduce those seriously injured or killed in car accidents. Another unsafe road practice with potentially lethal consequences is riding in a car with a driver who has been consuming alcohol. Recent findings suggest that this is a common activity for adolescents, with $24 \%$ of students indicating that they had been a passenger in a car where the driver had been drinking alcohol [21]. The associations between popularity and unsafe road practices among adolescents are unknown.

Relatedly, engaging in stranger-related risk-taking behaviours, including talking to and traveling in a car with a stranger, could have serious outcomes such as abducttion and assault, with strangers accounting for $18 \%$ of child sexual abuse against young males, and for 9\% against young females [27]. In recent times "stranger danger" for adolescents has focused on internet safety, as online social media such as Facebook and MySpace have become central to youth interactions, with one in five Australian children visiting or using social networking websites [28]. Internet safety initiatives in Australia have targeted children and adolescents, such as in the Cybersmart safety and security education program, managed by the Australian Communications and Media Authority. However, education regarding the dangers of strangers in the real world is targeted at children, such as traveling to and from school safely, such as the Walking School Bus program for primary school children [29]. Understanding peer status and stranger-related risk-taking is important, as almost three quarters of grade 7 to 10 students have been contacted by a stranger through e-mail or chat rooms [30]. Furthermore, as both popular and liked adolescents are sociable [31], and have many friends [5], they may be exposed to more strangers than those with lower status and therefore may be more vulnerable to the associated dangers. However, there is currently no knowledge regarding stranger-related risk-taking and peer status.

This study aims to broaden our understanding of the relationships between peer status and a wide range of risk-taking activities, by building on previous research exploring associations between popularity and aggression, cigarette use, alcohol consumption, marijuana use, sexual intercourse, and body image-related risk-taking, as well as investigating previously untested associations between peer status and ecstasy use, unprotected sex, road safety, stranger-related risk-taking, and antisocial activities. In light of previous findings, this study was designed to test the hypothesis that popularity but not likeability would be associated with a range of risk-taking activities, with higher popularity linked with more frequent risk-taking. In regards to gender, it was hypothesised that no significant differences would emerge, as consistent with previous research.

\section{METHOD}

\subsection{Participants}

Participants were 642 grade 9 students (53\% girls), ranging in age from 13 to 16 years $(\mathrm{M}=14.15$ years, SD $=0.54$ years). Students were from six local secondary schools; four co-educational (three public and one private) and two single-sex private schools (one for each sex).

\subsection{Coding System for Popularity and Likeability}

Schools provided the primary researcher with a list of grade 9 students, each being assigned a randomly generated three- or four-digit number in order for students to identify themselves and their peers without using their names. Students were provided with a list of their peers with their corresponding codes for use only during the survey period. On completion of the questionnaire, they were asked to place the lists in boxes to ensure they were kept separate from the questionnaires. The lists were not available to teachers and the codes were kept separate from the students' names in separate password protected computer files.

In accordance with other research [12,32], participants were asked to find the three "most popular" and three "most well-liked" same-gendered students in their grade and to write their associated codes. Due to concerns raised by the University Human Research Ethics Committee and State Department of Education, information regarding the least popular and least liked students was unable to be obtained. Contrary to previous research [9, 31], z-scores were not calculated from the raw popularity and likeability nominations, as the data were significantly positively skewed (popularity skewness $=5.5$ for girls, 3.6 for boys; likeability skewness $=3.3$ for girls, 2.4 for boys). As z-scores are highly sensitive to outliers and this could not be resolved using a min-max procedure due to the absence of least popular and least liked nominations [33], popularity and likeability were converted to trichotomous variables. The median of the nonzero nominations provided the researchers with a logical 
formula for categorizing the remaining nominations. The median for popularity was 2 , therefore popularity was split into low (0 nominations; 163 girls, 93 boys), medium (1 or 2 nominations; 96 girls, 115 boys) and high (more than 2 nominations; 79 girls, 96 boys). The median for likeability was 3 , and was split into low (0 nominations; 116 girls, 70 boys), medium (1 or 2 nominations; 105 girls, 121 boys) and high (3 or more nominations; 117 girls, 113 boys).

\subsection{Procedure}

Permission to undertake the study was provided by the University Human Research Ethics Committee and Department of Education. At the request of three schools, the Governing bodies consented to a passive consent protocol. Written information about the study was sent to parents approximately three weeks prior to survey completion and they were asked to return an attached slip should they decline the invitation for their children to participate.

Participants were offered the opportunity to complete the survey during regular class periods as part of their Pastoral Care programs. Active personal consent from each participant was obtained after the study, including the coding system, was explained. The students were assured confidentiality and told that their codes would not be linked back to their names. Those who did not wish to participate were provided alternative activities by their class teachers. Students individually completed a questionnaire booklet consisting of the measures described below.

\subsection{Measures}

After stating their gender, age, and the numerical code assigned to them, students completed the following measures.

Risk-Taking Activities. Participants were asked to indicate how frequently they engaged in stated risk-taking activities on a 5-point scale from "never" (1) to "very often" (5), following existing inventories and methodologies adopting 5-point scales $[34,35]$. The risk-taking items were informed by previous research investigating adolescent and youth risk-taking. Two items measured aggressive behaviours; namely, fighting verbally [36] and physically [9] with peers. Four items measured antisocial activities; namely, skipping class [37], vandalising property [37], stealing or shoplifting [18], and breaking school rules for no specific reason. Four items measured substance-related risks; namely, smoking cigarettes [15, 20], drinking alcohol with the intention of becoming drunk [26,36,37], smoking marijuana [20], and taking ecstasy. Three items measured road safety; namely, riding a bicycle without a helmet [34], traveling in a car without a seat-belt [26,38], and traveling in a car where the driver was unsafe [26,36,38], with examples of speeding or driving while intoxicated provided. Two items measured risks related to strangers; namely, talking to strangers [36] and accepting a ride in a car with a stranger [39]. Two items measured sexual risk-taking behaviours, with respondents indicating "yes" or "no" to their engagement in sexual intercourse [15] and unprotected sex [36], with an example of having intercourse without contraception provided.

Drive for Thinness Subscale of the Eating Disorders Inventory-3. Body image-related risk-taking for girls was measured with the Drive for Thinness subscale of the Eating Disorders Inventory-3 [40]. The seven items measure "excessive concern with dieting, preoccupation with weight and entrenchment in an extreme pursuit of thinness" [41]. This subscale has seven self-report items on a 6-point scale from "never" (1) to "always" (6), although items are assigned scores between 0 and 3 , with higher scores reflecting a higher drive for thinness. Items include "I think about dieting" and "I feel extremely guilty after overeating", and the wording of the last item of the subscale was changed from "pound" to "kilogram", to reflect the metric measurement system used in Australia. The Drive for Thinness subscale has been demonstrated to have sound psychometric properties, with Cronbach's alpha for internal reliability ranging from 0.80 to 0.92 in previous studies $[40,41]$, and 0.89 in the current study.

Drive for Muscularity Scale. Body image-related risktaking for boys was measured using the Drive for Muscularity Scale [42], which is a 15-item self-report inventory measuring attitudes and behaviours regarding an individual's perception that he or she is not muscular enough and the subsequent desire for increased muscle mass. Sample items are "I lift weights to build up muscle" and "I drink weight-gain or protein shakes", and are scored from "always" (1) to "never" (6), with all questions reverse-scored in order for higher scores to reflect desire for higher muscularity. The Drive for Muscularity Scale has been demonstrated to have sound psychometric properties [43], with Cronbach's alpha for internal reliability ranging from 0.78 to 0.87 in previous studies $[42,43]$, and 0.92 in the current sample.

\subsection{Statistical Analysis}

To investigate the roles of popularity, likeability, and gender in predicting risk-taking, the data were prepared for separate 3 (popularity) $\times 3$ (likeability) $\times 2$ (gender) between-groups analysis of variance (ANOVA) on the continuous risk-taking items, and two logistic regression analyses investigating the roles of these variables in predicting the categorical risk-taking items of sexual intercourse and unprotected sex. All statistical analyses were 
conducted using Predictive Analytics SoftWare (PASW).

Due to the high number of dependent variables, the Bonferroni correction reduced the significance level to 0.004 [44]. Observation of high correlations between some of the variables and groupings from previous research indicated that the continuous dependent variables could be reduced into seven categories, which changed the Bonferroni correction to 0.007. These seven categories were aggression (verbal and physical fighting), antisocial activities (skipping class, vandalising property, stealing or shoplifting, and breaking school rules), drinking alcohol, riding a bicycle without a helmet, unsafe motor vehicle practices (travelling in a car without a seat-belt and travelling in a car where the driver was unsafe), and strangers (talking to, and accepting a ride in a car with, a stranger). The weight-related risk-taking activities (Drive for Thinness and Drive for Muscularity) were investigated separately for each gender, as females completed the Drive for Thinness and males completed the Drive for Muscularity. Correlations between the dependent variables were observed and are presented in Table 1. As the correlations were mostly low, with some moderate and few large correlations, separate univariate analyses of variance were conducted, rather than a multiple analysis of variance [44].

\section{RESULTS}

\subsection{Preparing the Data for Analyses}

Prior to conducting analyses, the dependent variables were screened for missing values, outliers, normality, and linearity. All variables contained less than $5 \%$ missing values aside from the Drive for Thinness and Drive for Muscularity Scales, which had 6.5\% and 8.9\% missing values. Missing Values Analysis using PASW (Predictive Analytics SoftWare) revealed no systematic relationship between these variables and the independent variables, therefore the cases containing missing values were deleted from further analyses. Three variables were highly skewed and revealed minimal variance, with the majority of students reporting that they never smoked cigarettes (89\%), marijuana (93\%) or used ecstasy (98\%). The remaining variables were relatively normally distributed, with the most highly skewed variable (drinking alcohol with the intention of becoming drunk) having a skewness statistic of 2.2. The means and standard deviations on the risk-taking measures across the categories of popularity, likeability, and gender are presented in Table 2.

\subsection{Relationship between Popularity and Likeability}

Popularity and likeability were highly correlated for girls $(r=0.51)$, and for boys $(r=0.58)$, similar to other investigations of adolescent peer status [15,32]. The cross-tabulation of the relationship between popularity and likeability for females and males is presented in Table 3.

\subsection{Main and Interaction Effects of Popularity, Likeability, and Gender on the Categorical Variables}

The first logistic regression model contained all three independent variables to predict sexual intercourse, and was significant, $\chi^{2}(13, N=619)=53.43, p<0.001$, indicating that the model was able to distinguish those who engaged in intercourse from those who did not. The model explained between 8.3\% (Cox and Snell $R$ square) and $16 \%$ (Nagelkerke $R$ square) of the variance in intercourse, and correctly classified $88.2 \%$ of cases. The logistic regression coefficients from this model are presented in Table 4.

There was a significant main effect for popularity on sexual intercourse, $\chi^{2}(2, N=619)=8.76, p=0.013$, with those with high popularity (52\%) more likely to have sexual intercourse than those with low (16\%) popularity, $\chi^{2}(2, N=619)=8.07, p=0.004$. Those with medium popularity (32\%) were slightly more likely to have sexual intercourse than those with low popularity, $\chi^{2}(2, N=$ $619)=3.06, p=0.08$, although this was only marginally significant. The strongest predictor of having sexual intercourse was high popularity, recording an odds

Table 1. Pearson product-moment correlations between risk-taking categories.

\begin{tabular}{|c|c|c|c|c|c|c|c|}
\hline Category & 1 & 2 & 3 & 4 & 5 & 6 & 7 \\
\hline 1. Aggression & - & 0.53 & 0.34 & 0.21 & 0.24 & 0.36 & 0.30 \\
\hline 2. Antisocial activities & & - & 0.61 & 0.22 & 0.29 & 0.51 & 0.37 \\
\hline 3. Alcohol intoxication & & & - & 0.21 & 0.29 & 0.41 & 0.33 \\
\hline 4. Weight-related & & & & - & 0.16 & 0.15 & 0.14 \\
\hline 5. No helmet & & & & & - & 0.23 & 0.15 \\
\hline 6. Unsafe car & & & & & & - & 0.28 \\
\hline 7. Strangers & & & & & & & - \\
\hline
\end{tabular}

Note. All correlations significant at the .01 level. 
Table 2. Means (and Standard Deviations) of risk-taking measures across gender, popularity and likeability.

\begin{tabular}{|c|c|c|c|c|c|c|c|c|c|c|c|c|c|c|c|c|c|c|}
\hline & \multicolumn{9}{|c|}{ Female } & \multicolumn{9}{|c|}{ Male } \\
\hline & \multirow{2}{*}{\multicolumn{3}{|c|}{ Low Popularity }} & \multirow{2}{*}{\multicolumn{3}{|c|}{$\begin{array}{l}\text { Medium Popularity } \\
\text { Likeability }\end{array}$}} & \multirow{2}{*}{\multicolumn{3}{|c|}{ High Popularity }} & \multirow{2}{*}{\multicolumn{3}{|c|}{ Low Popularity }} & \multirow{2}{*}{\multicolumn{3}{|c|}{$\begin{array}{c}\text { Medium Popularity } \\
\text { Likeability }\end{array}$}} & \multicolumn{3}{|c|}{ High Popularity } \\
\hline & & & & & & & & & & & & & & & & & & \\
\hline & Low & Med & High & Low & Med & High & Low & Med & High & Low & Med & High & Low & Med & High & Low & Med & High \\
\hline Aggression & $\begin{array}{c}3.13 \\
(1.30)\end{array}$ & $\begin{array}{c}3.39 \\
(1.40)\end{array}$ & $\begin{array}{c}3.45 \\
(0.96)\end{array}$ & $\begin{array}{c}3.26 \\
(1.32)\end{array}$ & $\begin{array}{c}3.36 \\
(0.99)\end{array}$ & $\begin{array}{c}3.12 \\
(1.07)\end{array}$ & $\begin{array}{c}4.50 \\
(2.12)\end{array}$ & $\begin{array}{c}3.64 \\
(1.69)\end{array}$ & $\begin{array}{c}3.63 \\
(1.42)\end{array}$ & $\begin{array}{c}4.10 \\
(1.51)\end{array}$ & $\begin{array}{c}3.71 \\
(1.42)\end{array}$ & $\begin{array}{c}4.57 \\
(1.99)\end{array}$ & $\begin{array}{c}3.81 \\
(1.80)\end{array}$ & $\begin{array}{c}4.02 \\
(1.85)\end{array}$ & $\begin{array}{c}4.28 \\
(1.62)\end{array}$ & $\begin{array}{l}4.00 \\
(0.0)\end{array}$ & $\begin{array}{c}4.44 \\
(1.65)\end{array}$ & $\begin{array}{c}4.04 \\
(1.65)\end{array}$ \\
\hline Antisocial & $\begin{array}{c}5.04 \\
(1.55)\end{array}$ & $\begin{array}{c}5.16 \\
(1.67)\end{array}$ & $\begin{array}{c}5.05 \\
(1.25)\end{array}$ & $\begin{array}{c}5.33 \\
(1.62)\end{array}$ & $\begin{array}{c}4.75 \\
(1.08)\end{array}$ & $\begin{array}{c}4.71 \\
(1.05)\end{array}$ & $\begin{array}{c}6.50 \\
(0.71)\end{array}$ & $\begin{array}{c}5.64 \\
(1.74)\end{array}$ & $\begin{array}{c}6.65 \\
(2.15)\end{array}$ & $\begin{array}{c}5.60 \\
(1.62)\end{array}$ & $\begin{array}{c}4.77 \\
(1.17)\end{array}$ & $\begin{array}{c}5.43 \\
(1.62)\end{array}$ & $\begin{array}{c}4.80 \\
(1.27)\end{array}$ & $\begin{array}{c}5.26 \\
(1.34)\end{array}$ & $\begin{array}{c}5.36 \\
(2.10)\end{array}$ & $\begin{array}{l}5.00 \\
(0.0)\end{array}$ & $\begin{array}{c}6.61 \\
(1.94)\end{array}$ & $\begin{array}{c}5.20 \\
(1.24)\end{array}$ \\
\hline Alcohol & $\begin{array}{c}1.31 \\
(0.63)\end{array}$ & $\begin{array}{c}1.24 \\
(0.55)\end{array}$ & $\begin{array}{c}1.23 \\
(0.69)\end{array}$ & $\begin{array}{c}1.43 \\
(0.73)\end{array}$ & $\begin{array}{c}1.38 \\
(0.62)\end{array}$ & $\begin{array}{c}1.23 \\
(0.43)\end{array}$ & $\begin{array}{c}2.00 \\
(1.41)\end{array}$ & $\begin{array}{c}2.00 \\
(1.47)\end{array}$ & $\begin{array}{c}1.74 \\
(0.80)\end{array}$ & $\begin{array}{c}1.38 \\
(0.88)\end{array}$ & $\begin{array}{c}1.26 \\
(0.82)\end{array}$ & $\begin{array}{c}1.71 \\
(1.50)\end{array}$ & $\begin{array}{c}1.13 \\
(0.50)\end{array}$ & $\begin{array}{c}1.31 \\
(0.74)\end{array}$ & $\begin{array}{c}1.24 \\
(0.83)\end{array}$ & $\begin{array}{l}2.00 \\
(0.0)\end{array}$ & $\begin{array}{c}1.39 \\
(0.70)\end{array}$ & $\begin{array}{c}1.53 \\
(0.95)\end{array}$ \\
\hline DT & $\begin{array}{c}7.04 \\
(7.71)\end{array}$ & $\begin{array}{c}7.43 \\
(7.07)\end{array}$ & $\begin{array}{c}8.45 \\
(7.90)\end{array}$ & $\begin{array}{c}8.96 \\
(7.57)\end{array}$ & $\begin{array}{c}8.85 \\
(7.92)\end{array}$ & $\begin{array}{c}5.59 \\
(6.45)\end{array}$ & $\begin{array}{r}11.33 \\
(5.51)\end{array}$ & $\begin{array}{l}10.28 \\
(8.81)\end{array}$ & $\begin{array}{c}9.58 \\
(7.91)\end{array}$ & & & & & & & & & \\
\hline DMS & & & & & & & & & & $\begin{array}{c}2.23 \\
(0.96)\end{array}$ & $\begin{array}{c}2.22 \\
(0.97)\end{array}$ & $\begin{array}{c}2.66 \\
(1.29)\end{array}$ & $\begin{array}{c}1.96 \\
(0.78)\end{array}$ & $\begin{array}{c}2.35 \\
(1.11)\end{array}$ & $\begin{array}{c}2.18 \\
(0.92)\end{array}$ & $\begin{array}{l}2.47 \\
(0.0)\end{array}$ & $\begin{array}{c}2.88 \\
(1.33)\end{array}$ & $\begin{array}{c}2.60 \\
(1.09)\end{array}$ \\
\hline No helmet & $\begin{array}{c}2.25 \\
(1.50)\end{array}$ & $\begin{array}{c}2.54 \\
(1.57)\end{array}$ & $\begin{array}{c}3.41 \\
(1.30)\end{array}$ & $\begin{array}{c}3.09 \\
(1.44)\end{array}$ & $\begin{array}{c}2.69 \\
(1.42)\end{array}$ & $\begin{array}{c}2.71 \\
(1.53)\end{array}$ & $\begin{array}{c}3.50 \\
(2.12)\end{array}$ & $\begin{array}{c}3.07 \\
(1.49)\end{array}$ & $\begin{array}{c}3.15 \\
(1.48)\end{array}$ & $\begin{array}{c}3.12 \\
(1.37)\end{array}$ & $\begin{array}{c}2.59 \\
(1.46)\end{array}$ & $\begin{array}{c}3.00 \\
(1.00)\end{array}$ & $\begin{array}{c}2.56 \\
(1.63)\end{array}$ & $\begin{array}{c}3.06 \\
(1.57)\end{array}$ & $\begin{array}{c}3.00 \\
(1.62)\end{array}$ & $\begin{array}{l}4.00 \\
(0.0)\end{array}$ & $\begin{array}{c}3.33 \\
(1.37)\end{array}$ & $\begin{array}{c}2.92 \\
(1.43)\end{array}$ \\
\hline Unsafe car & $\begin{array}{c}2.74 \\
(1.13)\end{array}$ & $\begin{array}{l}2.57 \\
(.88)\end{array}$ & $\begin{array}{c}3.14 \\
(1.46)\end{array}$ & $\begin{array}{c}3.17 \\
(1.47)\end{array}$ & $\begin{array}{c}2.76 \\
(1.33)\end{array}$ & $\begin{array}{l}2.63 \\
(.88)\end{array}$ & $\begin{array}{c}4.50 \\
(3.54)\end{array}$ & $\begin{array}{c}3.85 \\
(2.76)\end{array}$ & $\begin{array}{c}2.91 \\
(1.15)\end{array}$ & $\begin{array}{c}3.12 \\
(1.21)\end{array}$ & $\begin{array}{c}3.00 \\
(1.37)\end{array}$ & $\begin{array}{c}3.43 \\
(2.94)\end{array}$ & $\begin{array}{c}3.06 \\
(1.84)\end{array}$ & $\begin{array}{c}3.29 \\
(1.57)\end{array}$ & $\begin{array}{c}3.12 \\
(1.67)\end{array}$ & $\begin{array}{l}3.00 \\
(0.0)\end{array}$ & $\begin{array}{c}3.28 \\
(1.36)\end{array}$ & $\begin{array}{c}3.00 \\
(1.39)\end{array}$ \\
\hline Strangers & $\begin{array}{c}3.08 \\
(0.91)\end{array}$ & $\begin{array}{c}3.00 \\
(0.90)\end{array}$ & $\begin{array}{c}3.41 \\
(1.05)\end{array}$ & $\begin{array}{c}3.35 \\
(1.19)\end{array}$ & $\begin{array}{c}3.28 \\
(1.03)\end{array}$ & $\begin{array}{c}2.91 \\
(0.89)\end{array}$ & $\begin{array}{c}3.50 \\
(0.71)\end{array}$ & $\begin{array}{c}3.64 \\
(1.55)\end{array}$ & $\begin{array}{c}3.65 \\
(1.14)\end{array}$ & $\begin{array}{c}3.05 \\
(0.99)\end{array}$ & $\begin{array}{c}3.35 \\
(1.17)\end{array}$ & $\begin{array}{c}4.00 \\
(2.10)\end{array}$ & $\begin{array}{c}3.06 \\
(1.06)\end{array}$ & $\begin{array}{c}3.08 \\
(1.15)\end{array}$ & $\begin{array}{c}3.36 \\
(1.04)\end{array}$ & $\begin{array}{l}4.00 \\
(0.0)\end{array}$ & $\begin{array}{c}3.17 \\
(1.34)\end{array}$ & $\begin{array}{c}3.76 \\
(1.51)\end{array}$ \\
\hline
\end{tabular}

Note. DT = Drive for Thinness, DMS = Drive for Muscularity.

Table 3. Cell sizes of popularity and likeability for females and males.

\begin{tabular}{lcccccccc}
\hline & \multicolumn{3}{c}{$\begin{array}{c}\text { Females } \\
\text { Popularity }\end{array}$} & & \multicolumn{4}{c}{ Males } \\
Popularity \\
\hline Likeability & High & Medium & Low & Total & High & Medium & Low & Total \\
High & 57 & 37 & 23 & 117 & 68 & 36 & 9 & 113 \\
Medium & 19 & 31 & 55 & 105 & 26 & 60 & 35 & 121 \\
Low & 3 & 28 & 85 & 116 & 2 & 19 & 49 & 70 \\
Total & 79 & 96 & 163 & & 96 & 115 & 93 & \\
\hline
\end{tabular}

Table 4. Logistic regression predicting the likelihood of engaging in sexual intercourse.

\begin{tabular}{|c|c|c|c|c|c|c|c|}
\hline Predictor & $\beta$ & $S E \beta$ & Wald's $\chi^{2}$ & $d f$ & $p$ & OR & 95\% C.I for OR \\
\hline Gender & 0.04 & 0.77 & 0.00 & 1 & 0.96 & 1.04 & {$[0.23,4.71]$} \\
\hline Popularity & & & 8.76 & 2 & 0.013 & 8.76 & \\
\hline Medium vs. Low Popularity & 1.25 & 0.72 & 3.06 & 1 & 0.08 & 3.50 & {$[0.86,14.26]$} \\
\hline High vs. Low Popularity & 3.05 & 1.07 & 8.07 & 1 & 0.004 & 21.11 & {$[2.57,173.04]$} \\
\hline Likeability & & & 1.66 & 2 & 0.437 & 1.66 & \\
\hline Medium vs. Low Likeability & 0.21 & 0.73 & 0.08 & 1 & 0.78 & 1.23 & {$[0.29,5.16]$} \\
\hline High vs. Low Likeability & -1.39 & 1.29 & 1.15 & 1 & 0.28 & 0.25 & {$[0.02,3.16]$} \\
\hline Gender x Popularity & & & 0.57 & 2 & 0.75 & & \\
\hline Gender x Likeability & & & 6.5 & 2 & 0.039 & & \\
\hline Gender x Medium vs. Low Likeability & 0.85 & 0.82 & 1.1 & 1 & 0.30 & 2.33 & {$[0.47,11.57]$} \\
\hline Gender x High vs. Low Likeability & 2.22 & 0.92 & 5.8 & 1 & 0.016 & 9.19 & {$[1.51,56.02]$} \\
\hline Popularity x Likeability & & & 2.06 & 4 & 0.73 & & \\
\hline Constant & -3.23 & 0.53 & 36.93 & 1 & $<0.001$ & 0.04 & \\
\hline
\end{tabular}

Note . $\mathrm{OR}=$ odds ratio; $\mathrm{CI}$ = confidence interval. 
ratio of 21.11.

There was a significant 2-way interaction of gender $\mathrm{x}$ likeability on sexual intercourse, $\chi^{2}(2, N=73)=6.5, p=$ 0.039 . The effect of gender at high likeability was significant, $\chi^{2}(1, N=222)=13.38, p<0.001$, with higher rates of intercourse occurring for males at high likeability (37\%) compared with females (8\%). The effect of gender at low likeability was not significant, $\chi^{2}(1, N=$ $179)=0.05, p=0.82$, with participation in sexual intercourse no different between males (5\%) and females (11\%). Contrasts were significant for males and females at high versus low likeability, with males 9 times more likely to engage in intercourse if they had high likeability compared with females. These findings are displayed in Figure 1.

The second logistic regression model selected those who indicated they had engaged in sexual intercourse and contained all three independent variables to predict unprotected intercourse. Although there were relatively few numbers of those engaging in sexual intercourse, of these 73 participants, 52\% indicated that they had had unprotected intercourse. This model was not statistically significant $\chi^{2}(5, N=73)=3.36, p=0.65$, indicating that popularity, likeability, and gender did not predict the likelihood of engaging in unprotected intercourse from this smaller sample of adolescents.

\subsection{Main Effects of Popularity, Likeability, and Gender on the Continuous Variables}

Three-way analyses of variance revealed significant main effects of popularity on aggression, $F(2,609)=$ 5.53, $p=0.004, \eta \rho^{2}=0.018$, with post hoc comparisons using the Sidak correction indicating that those with high popularity $(\mathrm{M}=4.04, \mathrm{SD}=0.32)$ engaged in this behaviour significantly more frequently than those with low popularity $(\mathrm{M}=3.73, \mathrm{SD}=0.13), p=0.036$, but did not engage in this behaviour more than those with medium popularity $(\mathrm{M}=3.64, \mathrm{SD}=0.12), p=0.35$.

There were other main effects of popularity following this same pattern, whereby those with high popularity engaged in higher risk-taking compared with those in the low popularity category. These were drinking alcohol with the intention of becoming drunk, $F(2,610)=14.22$, $p<0.001, \eta \rho^{2}=0.04$, whereby high popularity $(\mathrm{M}=$ 1.78 , SD $=0.17$ ), was significantly higher than low popularity $(\mathrm{M}=1.35$, $\mathrm{SD}=0.07), p<0.001$, but not medium popularity $(\mathrm{M}=1.28, \mathrm{SD}=0.06), p=1.0$, and antisocial activities, $F(2,600)=13.98, p<0.001, \eta \rho^{2}=$ 0.045 , however, as discussed below this latter finding was subsumed by a three-way interaction. There was a similar main effect for popularity on strangers, $F(2,610)$ $=14.22, p<0.001, \eta \rho^{2}=0.04$, whereby those with high popularity $(\mathrm{M}=3.62$, $\mathrm{SD}=0.24)$ were significantly more likely to engage in this form of risk-taking than those with low popularity $(\mathrm{M}=3.32, \mathrm{SD}=0.10), p<$ 0.001 , but not medium popularity $(\mathrm{M}=3.17, \mathrm{SD}=0.09)$, $p=1.0$.

There was no significant main effect of likeability on any of the risk-taking behaviours. However, there was a significant main effect of gender on aggression, such that males $(\mathrm{M}=4.57, \mathrm{SD}=0.19)$ engaged in more verbal and physical aggression than females $(\mathrm{M}=3.69, \mathrm{SD}=0.14)$, $F(1,609)=17.22, p<0.001, \eta \rho^{2}=0.027$.

\subsection{Interaction Effects of Popularity, Likeability, and Gender on the Continuous Variables}

There were no significant two-way interactions between popularity and likeability or between popularity and gender on any of the risk-taking behaviours, nor between likeability and gender on any of the continuous variables. There was only one significant popularity $\times$ likeability $\times$ gender interaction effect on risk-taking behaviours, namely antisocial activities, $F(4,600)=4.95, p$ $=0.001, \eta \rho^{2}=0.032$, which is displayed in Figure 2 . Using the per family error rate method, there was a significant popularity $\times$ likeability interaction for males, $F(4$, $600)=4.28, p<0.001$, but not females, $F(4,600)=$ $0.011, p>0.25$, as determined by the F-distribution critical value, which was 2.79 [45]. Investigations of this interaction for males indicated that there was a main effect of likeability at high popularity, $F(2,600)=6.18, p$ $<0.01$, and no main effects of likeability at low popularity, $F(2,600)=2.41, p>0.025$, or medium popularity, $F(2,600)=1.21, p>0.25$. Pairwise comparisons using the Sidak correction for multiple tests revealed that only the comparison of high $(\mathrm{n}=108 ; \mathrm{M}=6.28$; $\mathrm{SD}=0.31$ ) and medium ( $\mathrm{n}=116 ; \mathrm{M}=8.20 ; \mathrm{SD}=0.50)$ likeability at high popularity was different, $p=0.021$, indicating less engagement in antisocial activities among highly popular boys who were high versus medium on likeability.

\section{DISCUSSION}

This study investigated the roles of popularity and likeability in adolescent males and females across eight domains of risk-taking. It sought to build on previous research by simultaneously investigating two domains of peer status (i.e., popularity and likeability) and including risk-taking behaviours that have thus far received little attention in relation to peer status.

The main effect of popularity on five out of the eight domains of risk-taking indicated that this form of peer status is clearly associated with risk-taking across a wide array of domains, with higher popularity significantly associated with greater risk-taking. Students with high 


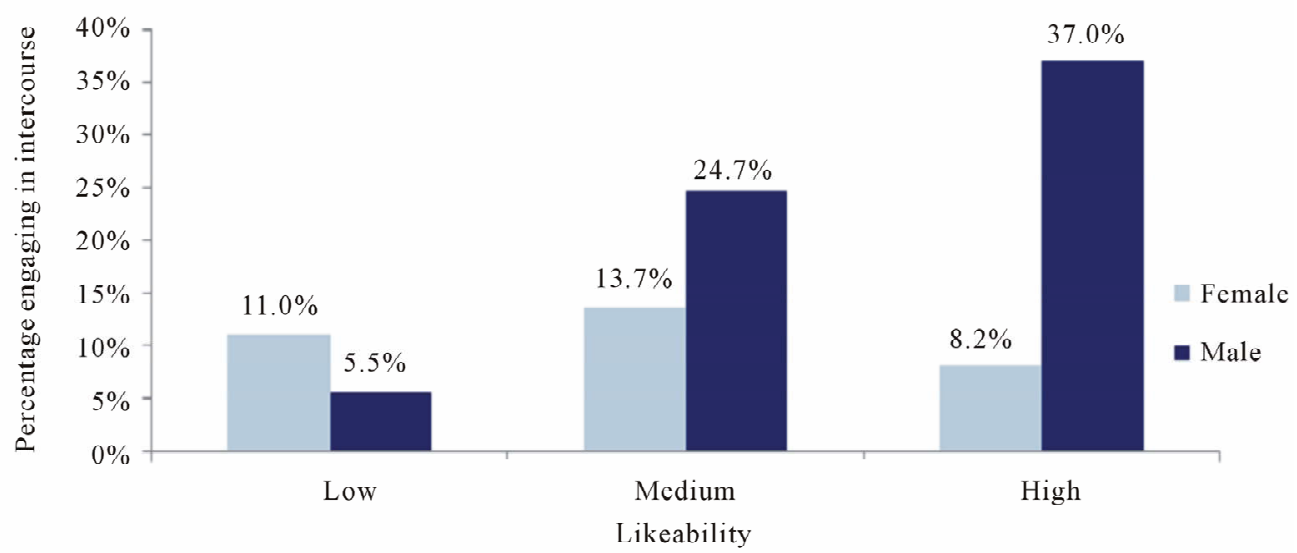

Figure 1. The percentage of males and females at different levels of likeability engaging in sexual intercourse.

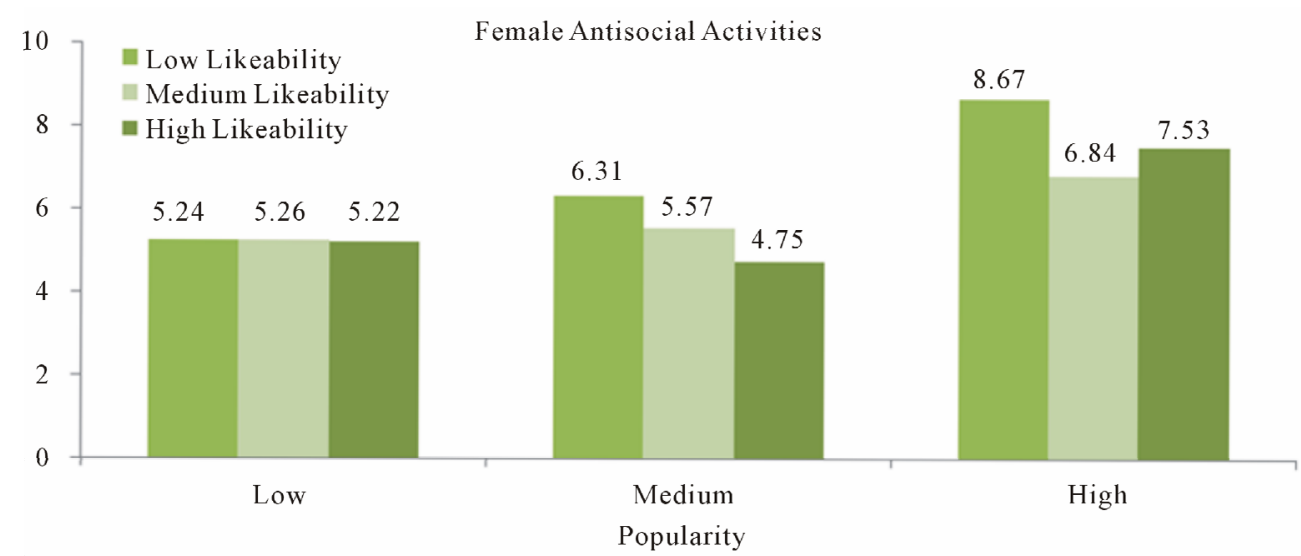

(a)

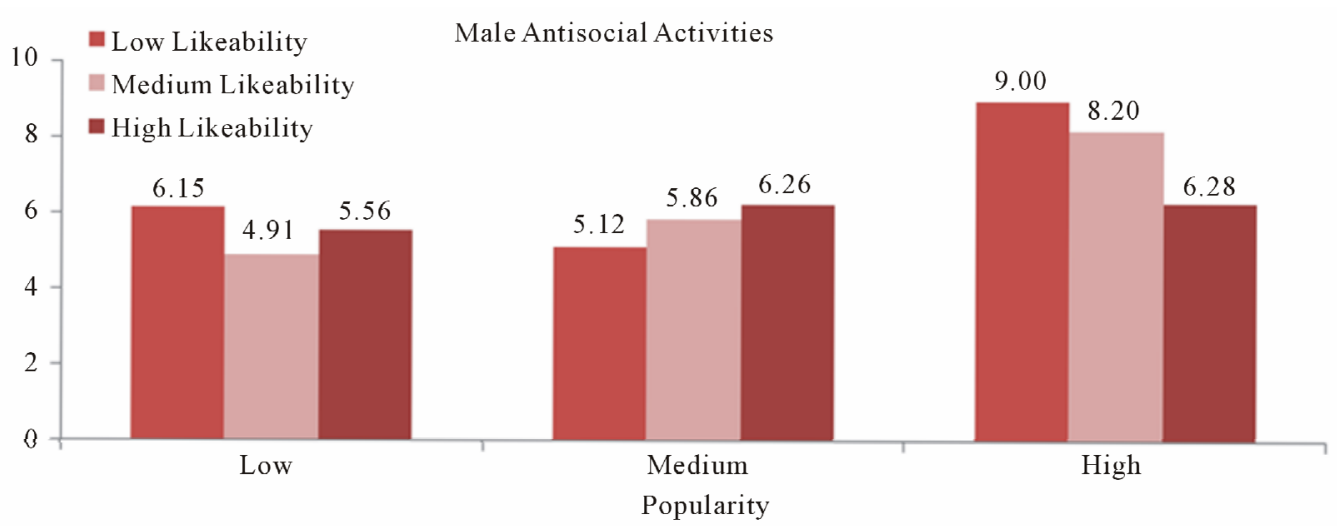

(b)

Figure 2. Three-way interaction of popularity x likeabilety x gender on antisocial activities.

popularity were more likely to engage in aggressive behaviours (verbal and physical aggression) compared with students with low popularity, with boys more likely to participate in this form of risk-taking than girls. These findings support several other studies indicating that aggression is a common characteristic of many popular adolescents [6,9]. However, given the absence of a sig- nificant interaction between popularity and gender, the findings suggest that aggressive behaviours are equally characteristic of popular boys and girls, consistent with previous research associating aggression with popular boys [6], girls [10], and both genders [9].

Similarly, popularity was associated with alcohol use as well as sexual intercourse, suggesting a dangerous 
combination of risk-taking, whereby popular adolescents may be at heightened vulnerability to the possible negative consequences of sexual activities, such as unwanted pregnancy and subsequent feelings of regret regarding their sexual activities, due to alcohol intoxication [46]. This is an important association given that almost one quarter of sexually active American adolescents had consumed alcohol or used other drugs before their last sexual experience [23]. Although popularity was not associated with unprotected sexual intercourse in this study, this could be due to the small number of adolescents participating in sexual activities, as associations between alcohol consumption and unprotected intercourse have been previously found [47]. The association between high popularity and higher stranger-related risk-taking provided evidence for including this form of risk-taking in future studies, as no previous studies to our knowledge have considered this association. Despite internet safety initiatives regarding the sharing of personal information and the dangers of communicating with unknown persons online, almost three quarters of grade 7 to $10 \mathrm{stu}-$ dents have been contacted by a stranger online [30]. A recent study of adolescents aged 12 to 18 identified three main reasons for communicating with strangers on the internet; namely to meet new people, to compensate for social anxiety, and for entertainment purposes [48]. These authors noted that introversion did not influence engagement in this form of risk-taking, and that it is perhaps sensation-seeking that should be considered. As both popular and liked adolescents have been described as socially competent [49], and having many friends [5], they are likely to be faced with many opportunities to meet and interact with peers in the real world. The sensation-seeking hypothesis should be investigated further, as it may be able to explain the generally higher participation of popular adolescents as compared with other peers in a broad range of risk-taking activities. Furthermore, it is unknown whether popular adolescents in the present study were engaging in stranger-related risk-taking on the internet or with strangers in the real world. This information would be useful to obtain in future studies.

While high popularity was generally associated with significantly higher engagement in a wide array of risk-taking activities, popularity was not associated with body image-related risk-taking or with unsafe road safety, including riding a bicycle without a helmet and traveling in a car with an unsafe driver. There are several possible explanations for these findings. First, riding a bicycle without a helmet is fairly common among all adolescents [21], as are body dissatisfaction and body-change behaviours [50]. Given their normative nature, participation in these activities does not necessarily lead to elevated standing or increased social visibility among peers. As one study [24] found that popularity was associated with body size and dieting behaviours for students in grades 11 and 12, it would be beneficial to explore the less normative body image-related risk-taking behaviours, such as fasting or self-induced vomiting for those seeking thinness, and excessive weight-lifting and steroid use for those seeking muscularity, in future studies, particularly with older adolescents.

As Australian youth are able to obtain a learner's driving permit at 16 , it is possible that participants in this study were too young to be exposed to unsafe drivers. Alternatively, it could be that unsafe road practices are considered to be too dangerous and rejected by popular youth, who are leaders of current trends and risk-taking activities. These hypotheses remain speculative until more research is conducted in this area of risk-taking to determine whether popularity influences unsafe road practices.

As predicted, there were no main effects of likeability on risk-taking, as this form of peer status on its own has not been associated with higher risk-taking activities in previous studies [15]. Although likeability did not predict engagement in risk-taking activities on its own, there was a significant interaction between likeability and gender for sexual intercourse. Specifically, compared with medium and low levels of likeability, boys with high likeability were most likely to participate in this activity whereas girls with high likeability were least likely to have sexual intercourse. This finding suggests that participation in sexual intercourse is damaging for social acceptance but not popularity for girls, and may lead to opposite outcomes for boys. Sexual availability may be one avenue for achieving social visibility for both popular boys and girls, and may be suggestive of a "prototype" of popularity [22]. However, it may be perceived by both genders to be a more socially acceptable activity for boys only, and therefore it was associated with higher likeability for boys but not girls in this study. It is worth noting that research to date, including the current study, has only considered popularity and heterosexual attracttiveness and success, with same-sex experiences ignored. Expanding upon the conceptualisations of sexual engagement in future research would improve our understanding of the links between peer status and sexual activities.

The differential effects of popularity, likeability, and gender combined in this study to form a significant threeway interaction on antisocial activities. Highest engagement in this form of risk-taking occurred for adolescents with high popularity and low likeability, particularly for males. This combination of high popularity and low likeability appears to subject adolescents to a vulnerability to antisocial activities, including skipping class, vandalising property, stealing or shoplifting, and breaking school rules for no specific reason. These activities are 
perhaps more socially visible than other forms of risktaking, as some occur within the school setting and are therefore more easily observed by a greater number of peers. Furthermore, participating in antisocial activities may be perceived as being rebellious, contributing to the image of "toughness" [6] and "coolness" [5], that some adolescents may aspire toward. It will be fruitful for future studies to continue investigating this form of risktaking and the possible longer term sequelae of these activities, despite speculations that associations between popularity and risk-taking are limited to the adolescent period [15].

As most adolescents reported that they never smoked cigarettes or marijuana or used ecstasy, it was not possible to investigate associations between substance use and popularity. It appears that messages regarding the dangers of engaging in these activities have been effective for young Australian adolescents. For example, there is a National Drugs Campaign targeting youth aged 15 to 21 years and their use of drugs such as ecstasy [51], and a National Tobacco Campaign, which has targeted several populations, including young people aged 12 to 24 years, with the message "to reject smoking" [52].

While providing more comprehensive support for associations between popularity and risk-taking, the current study has some limitations. First, the cross-sectional nature of this study limits the interpretation of these findings to associations between peer status and risk-taking activities. Therefore, from these data we cannot interpret causality, such as whether popularity causes risk-taking or vice versa. Furthermore, this study relies on self-reported measures; some students may have felt uncomfortable reporting their participation in risk-taking activeties and subsequently provided inaccurate responses, as noted previously [15].

In summary, this study investigated two types of peer status, namely, popularity and likeability, and their associations with eight domains of risk-taking in Australian grade 9 male and females. There were strong main effects for popularity on five out of the eight domains of risk-taking, whereas likeability was not uniquely associated with any of the domains. This study provides support for established links between popularity and aggressive behaviours, alcohol use, and sexual intercourse, and also extends knowledge regarding a broader range of risk-taking domains by presenting novel associations between popularity and stranger-related risk-taking, and the complex relationships between popularity, likeability, gender and antisocial activities. These new findings point to the consideration of a broader range of risk-taking activities when investigating popularity.

\section{ACKNOWLEDGEMENTS}

The authors wish to thank the teachers, parents and students for par- ticipating in this research project.

\section{REFERENCES}

[1] Arnett, J. (1992) Reckless behavior in adolescence: A developmental perspective. Developmental Review, 12, 339373. doi:10.1016/0273-2297(92)90013-R

[2] Selfhout, M.H.W., Branje, S.J.T. and Meeus, W.H.J. (2008) The development of delinquency and perceived friendship quality in adolescent best friendship dyads. Journal of Abnormal Child Psychology, 36, 471-485. doi:10.1007/s10802-007-9193-5.

[3] LaFontana, K.A. and Cillessen, A.H.N. (2002) Children's perceptions of popular and unpopular peers: A multimethod assessment. Developmental Psychology, 38, 635-647. doi:10.1037//0012-1649.38.5.635

[4] Parkhurst, J.T. and Hopmeyer, A. (1998) Sociometric popularity and peer-perceived popularity: Two distinct dimensions of peer status. Journal of Early Adolescence, 18, 125-144. doi:10.1177/0272431698018002001

[5] De Bruyn, E.H. and Cillessen, A.H.N. (2006) Popularity in early adolescence: Prosocial and antisocial subtypes. Journal of Adolescent Research, 21, 607-627. doi:10.1177/0743558406293966

[6] Rodkin, P.C., Farmer, T.W., Pearl, R. and Van Acker, R. (2000) Heterogeneity of popular boys: Antisocial and prosocial configurations. Developmental Psychology, 36, 14-24. doi:10.1037//0012-1649.36.1.14

[7] LaFontana, K.M. and Cillessen, A.H.N. (1998) The nature of children's stereotypes of popularity. Social Development, 7, 301-320. doi:10.1111/1467-9507.00069

[8] Eder, D. (1985) The cycle of popularity: Interpersonal relations among female adolescents. Sociology of Education, 58, 154-165. doi:10.2307/2112416

[9] Cillessen, A.H.N. and Mayeux, L. (2004) From censure to reinforcement: Developmental changes in the association between aggression and social status. Child Development, 75, 147-163. doi:10.1111/j.1467-8624.2004.00660.x

[10] Merten, D.E. (1997) The meaning of meanness: Popularity, competition, and conflict among junior high school girls. Sociology of Education, 70, 175-191. doi: $10.2307 / 2673207$

[11] Xie, H., Cairns, R.B. and Cairns, B.D. (2002) The development of social aggression and physical aggression: A narrative analysis of interpersonal conflicts. Aggressive Behavior, 28, 341-355. doi:10.1002/ab.80008

[12] Cillessen, A.H.N. and Marks, P.E.L. (2011) Conceptualizing and measuring popularity. In: Cillessen, A.H.N., Schwartz, D. and Mayeux, L., Eds., Popularity in the Peer System, The Guilford Press, New York, 25-56.

[13] Sandstrom, M.J. (2011) The power of popularity: Influence processes in childhood and adolescence. In: Cillessen, A.H.N., Schwartz, D. and Mayeux, L., Eds., Popularity in the Peer System, The Guilford Press, New York, 219-244.

[14] Coleman, J.S. (1961) The adolescent society: The social life of the teenager and its impact on education. The Free 
Press of Glencoe, New York.

[15] Mayeux, L., Sandstrom, M.J. and Cillessen, A.H.N. (2008) Is being popular a risky proposition? Journal of Research in Adolescence, 18, 49-74.

doi:10.1111/j.1532-7795.2008.00550.x

[16] Estell, D.B., Farmer, T.W., Pearl, R., Van Acker, R. and Rodkin, P.C. (2008) Social status and aggressive and disruptive behavior in girls: Individual, group, and classroom influences. Journal of School Psychology, 46, 193212. doi:10.1016/j.jsp.2007.03.004

[17] Adler, P.A. (1995) Dynamics of inclusion and exclusion in preadolescent cliques. Social Psychology Quarterly, 58, 145-162. doi:10.2307/2787039

[18] Allen, J.P., Porter, M.R., McFarland, F.C., Marsh, P. and McElhaney, K.B. (2005) The two faces of adolescents' success with peers: Adolescent popularity, social adaptation, and deviant behavior. Child Development, 76, 747760. doi:10.1111/j.1467-8624.2005.00875.x

[19] Killeya-Jones, L.A., Nakajima, R. and Costanzo, P.R. (2007) Peer standing and substance use in early-adolescent grade-level networks: A short-term longitudinal study. Prevention Science, 8, 11-23. doi:10.1007/s11121-006-0053-2

[20] Diego, M.A., Field, T.M. and Sanders, C.E. (2003) Academic performance, popularity, and depression predict adolescent substance use. Adolescence, 38, 35-42. http://www.ncbi.nlm.nih.gov/pubmed/12803452

[21] U.S. Department of Health and Human Services, Centres for Disease Control and Prevention (2012) Youth risk behavior surveillance system-United States, 2011(morbidity and mortality weekly report surveillance summaries, 61). http://www.cdc.gov/healthyyouth/yrbs/overall.htm

[22] Prinstein, M.J., Meade, C.S. and Cohen, G.L. (2003) Adolescent oral sex, peer popularity, and perceptions of best friends' sexual behaviour. Journal of Pediatric Psychology, 28, 243-249. doi:10.1093/jpepsy/jsg012

[23] Kann, L., Kinchen, S.A., Williams, B.I., Ross, J.G., Lowry, R., Hill, C. and Kolbe, L.J. (1998) Youth risk behaviour surveillance-United States, 1997. The Journal of School Health, 68, 355-369. doi:10.1111/j.1746-1561.1998.tb07202.x

[24] Wang, S.S., Houshyar, S. and Prinstein, M.J. (2006) Adolescent girls' and boys' weight-related health behaviours and cognitions: Associations with reputation- and preference-based peer status. Health Psychology, 25, 658-663. doi:10.1037/0278-6133.25.5.658

[25] Australian Transport Safety Bureau. (2004) Road safety in Australia: A publication commemorating world health day.

http://www.infrastructure.gov.au/roads/safety/publication s/2004/Safety_Aust.aspx

[26] Simons-Morton, B.G., Ouimet, M.C., Zhang, Z., Klauer, S.E., Lee, S.E., Wang, J. and Dingus, T.A. (2011) The effect of passengers and risk-taking friends on risky driving and crashes/near crashes among novice teenagers. Journal of Adolescent Health, 49, 587-593. doi:10.1016/j.jadohealth.2011.02.009

[27] Australian Bureau of Statistics (2005) Personal safety survey Australia (2005 reissue, 4906.0).

http://www.abs.gov.au/AUSSTATS/abs@.nsf/Lookup/490 6.0Main+Features12005\%20(Reissue)?OpenDocument

[28] Australian Bureau of Statistics (2011) Australian social trends (ABS catalogue No. 4102.0). http://www.abs.gov.au/ausstats/abs@.nsf/mf/4102.0

[29] Australian Government Department of the Environment and Heritage, Australian Greenhouse Office (2005) Walking school bus: A guide for parents and teachers. http://www.travelsmart.gov.au/schools/pubs/guide.pdf

[30] Stahl, C. and Fritz, N. (2002) Internet safety: Adolescents' self-report. Journal of Adolescent Health, 31, 7-10. doi:10.1016/S1054-139X(02)00369-5

[31] Closson, L.M. (2009) Status and gender differences in early adolescents' descriptions of popularity. Social Development, 18, 412-426. doi:10.1111/j.1467-9507.2008.00459.x

[32] Babad, E. (2001) On the conception and measurement of popularity: More facts and some straight conclusions. Social Psychology of Education, 5, 3-30. doi:10.1177/0272431698018002001

[33] Jain, A., Nandakumar, K. and Ross, A. (2005) Score normalization in multimodal biometric systems. Pattern Recognition, 38, 2270-2285. doi:10.1016/j.patcog.2005.01.012

[34] Finch, C., Ferla, J., Chin, G., Maloney, P. and Abeysiri, P. (1994) Teenagers' attitudes towards bicycle helmets (report No. 64). http://www.monash.edu.au/miri/index.html

[35] Prinstein, M.J. and Wang, S.S. (2005) False consensus and adolescent peer contagion: Examining discrepancies between perceptions and actual reported levels of friends' deviant and health risk behavior. Journal of Abnormal Child Psychology, 33, 293-306. doi:10.1007/s10802-005-3566-4

[36] Mazanov, J. and Byrne, D. (2006) An evaluation of the stability of perceptions and frequency of adolescent risktaking over time and across samples. Personality and Individual Differences, 40, 725-735. doi:10.1016/j.paid.2005.07.018

[37] Sinha, J.W., Cnaan, R.A. and Gelles, R.J. (2007) Adolescent risk behaviors and religion: Findings from a national study. Journal of Adolescence, 30, 231-249. doi:10.1016/j.adolescence.2006.02.005

[38] Hartos, J., Eitel, P. and Simons-Morton, B. (2002) Parenting practices and adolescent risky driving: A threemonth prospective study. Health Education \& Behavior, 29, 194-206. doi:10.1177/109019810202900205

[39] Valentine, G. (1997) “Oh yes I can”. “Oh no you can’t”: children and parents' understanding of kids' competence to negotiate public space safely. Antipode, 29, 65-89.

[40] Garner, D.M. (2004) Eating disorder inventory. 3rd Edition, Psychological Assessment Resources, Lutz.

[41] Garner, D.M., Garfinkel, P.E. and Olmsted, M.P. (1983) An overview of sociocultural factors in the development of anorexia nervosa. In: Darby, P.L., Garfinkel, P.E., Garner, D.M. and Coscina, D.V., Eds., Anorexia Nervosa: Recent Developments in Research, Alan R. Liss, New York, 65-82. 
[42] McCreary, D.R. and Sasse, D.K. (2000) An exploration of the drive for muscularity in adolescent boys and girls. Journal of American College Health, 48, 297-304. doi:10.1080/07448480009596271

[43] McCreary, D.R., Sasse, D. K., Saucier, D.M. and Dorsch, K.D. (2004) Measuring the drive for muscularity: Factorial validity of the Drive for Muscularity Scale in men and women. Psychology of Men \& Masculinity, 5, 49-58. doi:10.1037/1524-9220.5.1.49

[44] Pallant, J. (2011) SPSS survival manual: A step by step guide to data analysis using the SPSS program. 4th Edition, Allen \& Unwin, Berkshire.

[45] Keppel, G. and Zedeck, S. (2002) Data analysis for research designs. 10th Edition, W. H. Freeman and Company, New York.

[46] Wellings, K., Nanchahal, K., Macdowall, W., McManus, S., Erens, B., Mercer, C.H., et al. (2001) Sexual behaviour in Britain: Early heterosexual experience. Lancet, 358, 1843-1850.

http://www.hawaii.edu/hivandaids/Sexual\%20Behaviour \%20in\%20Britain\%20\%20\%20Early\%20Heterosexual\% 20Experience.pdf

[47] Clapper, R.L. and Lipsitt, L.P. (1991) A retrospective study of risk-taking and alcohol-mediated unprotected intercourse. Journal of Substance Abuse, 3, 91-96. doi:10.1016/S0899-3289(05)80009-4

[48] Peter, J., Valkenburg, P.M. and Schouten, A.P. (2006) Characteristics and motives of adolescents talking with strangers on the internet. CyberPsychology \& Behavior, 9, 526-530. doi:10.1089/cpb.2006.9.526

[49] Aikans, J.W. and Litwack, S.D. (2011) Prosocial skills, social competence, and popularity. In: Cillessen, A.H.N., Schwartz, D. and Mayeux, L., Eds., Popularity in the Peer System, The Guilford Press, New York, 140-162.

[50] Rodin, J., Silberstein, L. and Striegel-Moore, R. (1984) Women and weight: A normative discontent. Nebraska Symposium on Motivation, 32, 267-307.

[51] Australian Government Department of Health and Ageing, National Drugs Campaign (2011) National drugs campaign. http://www.drugs.health.gov.au/

[52] Australian Government Department of Health and Ageing, More Targeted Approach and Break the Chain Campaigns, Social Marketing Unit (2012) Quit now. http://www.quitnow.gov.au 